Memória do Projeto FLORAM 


\section{As origens do Projeto FLORAM}

\section{JACQUES MARCOVTTCH}

empre haverá uma certa curiosidade em saber como

foram elaboradas as idéias centrais de um projeto de

florestamento da amplitude do Floram. Para muitos

é difícil entender por que o Instituto de Estudos Avançados foi o berço de um projeto endereçado às ciências ecológicas e biológicas.

Seria uma concessão aos modismos do último quartel de século? Ou o resultado de uma longa e arraigada consciência em relação ao futuro do planeta?

Quando o Projeto Floram começa a ser conhecido no Brasil e no Exterior, perguntas são formuladas a respeito de sua autoria e sobre os procedimentos adotados para chegar aos documentos divulgados. Despontam indagações sobre a metodologia adotada, considerando se tratar de uma proposiçăo pioneira, além de ser um empreendimento inédito nas atividades do IEA.

As respostas a tais perguntas e questionamentos baseiam-se nos depoimentos dos que tiveram um papel mais destacado na gestaçáo inicial do Floram. Ou seja, Aziz Ab'Sáber, José Goldemberg, Leopold Rodés e Werner Zulauf. Na base desse testemunho é que se apresenta aos leitores esta informação sobre as origens do Projeto Floram.

\section{Pressão internacional}

No segundo semestre de 1988 , em diversos países e inclusive no Brasil, a opinião pública denunciou com grande veemência os atentados à Natureza cometidos em escala internacional. Por isso, a comunidade científica passou a dar prioridade ao estudo de alternativas a práticas nocivas ao meio ambiente. Entre as várias reuniōes científicas convocadas para o debate dessa temática, teve inegável repercussão o congresso "Climate and Development", realizado em Hamburgo, em novembro de 1988 , a qual esteve presente o professor Wilfried Bach, da Universidade de Munster. 
Convocada para discutir o "efeito estufa", na reuniăo houve um confronto entre os pesquisadores comprometidos com a causa ambiental e o "lobby"da energia nuclear. A divergência decorria do fato de os defensores da maior utilizaçáo da energia nuclear endossarem as críticas à poluiçáo ambiental, causada pelo desmensurado uso de combustíveis fósseis, propondo o caminho da proliferação de centrais nucleares. Soluçáo rechaçada pelos pesquisadores face ao risco de novas catástrofes como a de Chernobyl.

Tal confronto levou o professor Bach a dirigir-se à delegaçáo brasileira no congresso para formular a seguinte questáo, obviamente um desafio: "por que o Brasil, com tamanha extensão territorial e com um clima que permite o crescimento rápido de florestas, não desenvolve um grande projeto de reflorestamento destinado a fixar em fitomassa o excesso de carbono flutuante na atmosfera ?" O questionamento foi registrado pelos delegados brasileiros, entre os quais Werner Zulauf, e chegou ao conhecimento dos que entre nós se dedicam a problemas energéticos e ambientais, graças ao artigo de sua autoria, publicado na Folha de S. Paulo, em dezembro daquele mesmo ano. Assim, pode-se atribuir a esse cientista alemão a proposta de se estudar um audacioso projeto de florestamento e a Zulauf o registro e a disseminação da proposta.

\section{IEA assume o projeto}

Tomando conhecimento da tese apresentada no conclave de Hamburgo - e após debatê-la com Werner Zulauf - o entáo reitor da USP, professor José Goldemberg, em maio de 1989, solicitou-me que o IEA iniciasse estudos sobre a questáo. A importância de o Brasil colaborar no esforço mundial contra o "efeito estufa", a experiência brasileira na constituição de florestas e a disponibilidade de recursos humanos qualificados e grupos de pesquisadores na área foram elementos básicos para a concepçáo do projeto.

Assim, a questão foi trazida para o IEA, passando a ser examinada por um grupo em que participavam Aziz Ab'Sáber, Werner Zulauf, Leopoldo Rodés e eu. Tendo como objetivo transformar a proposiçăo num projeto do Instituto, o grupo realizou diversas reunióes e o trabalho atravessou várias etapas. $O$ professor $A b$ 'Sáber assumiu a liderança na formulaçáo do conteúdo do projeto e algumas diretrizes foram preparadas sobre o desenvolvimento da temática e da metodologia. Ficou acertado que a confeç̧áo do projeto ficaria aberta à participaçáo de todos os engajados na questáo florestal - desde os ecologistas que combatem a devastaçăo florestal até os industriais que necessitam das florestas. 
A missão estabelecida foi a de preparar para o Brasil um projeto de recuperação da cobertura vegetal, notadamente das florestas. Cumpre assinalaŕ que no primeiro semestre de 1989 , na área de assuntos internacionais do IEA - sentia-se a premente necessidade de o Brasil sair da defensiva. O País se encontrava face à opiniáo pública internacional, sendo constantemente censurado por questóes ecológicas. Por isso, parecia evidente que uma contribuiçáo para se passar à ofensiva resultaria de uma atitude responsável, através de um programa expressivo de florestamento.

$\mathrm{Na}$ fase seguinte foi constituído no IEA um grupo mais amplo, com a participação de: Antonio Rensi Coelho, Geraldo Forbes, James Wright, Leopoldo Brandáo, Luiz Barrichelo, Mauro A. de Morais Victor e Nelson Barbosa. Esse grupo amplo foi então convidado para debater o conteúdo, o formato do Projeto Floram e discutir o documento preliminar.

\section{Confluência de contribuiçóes}

Para muitos é dificil entender por que o Instituto de Estudos Avançados foi $o$ berço de um projelo endereçado às ciências ecológicas e biológicas.

A constituição do grupo mais amplo possibilitou a confluência de percepçóes complementares, indispensável no estudo de um empreendimento interdisciplinar e intersetorial como o Floram. Assim, reuniu-se a visão de Aziz Ab’Sáber (geógrafo com militância ativa no campo da pesquisa e do reconhecimento do território nacional), com a experiência do Leopold Rodés (em que se destaca uma vivência em questóes tecnológicas, como pesquisador $\mathbf{e}$ industrial), com os conhecimentos do Werner Zulauf (que convive há muitos anos com o questionamento da defesa do meio ambiente). A eles foram somadas as reflexōes do professor José Goldemberg (físico, especialista em problemas energéticos com uma visáo multidisciplinar das questóes enfrentadas pelo Floram).

Em junho de 1989, o projeto Floram estava concebido e esboçado. Naquela ocasiáo, um dos membros do grupo - Leopoldo Brandáo foi à China, para examinar um projeto de implantaçäo de florestas, empreendimento motivado pela necessidade de aumentar a produção de madeira. Este projeto de 8 milhóes de hectares, financiado pelo Banco Mundial, tem por objetivo primordial a expansáo da disponibilidade de madeira (que na China é largamente utilizada como combustível na preparaçáo de alimentos e na calefaçáo doméstica). Como especialista èm reflorestamento na iniciativa privada, Leopoldo Brandão recolheu experiências dos programas chineses de reflorestamento em larga escala realizados com baixo 'custo por' " hectare. As informaçóes trazidas foram de inegável utilidade nas reunióes preparatorias do Floram. 
A contribuiçáo de Leopoldo Brandão foi também valiosa porque deu um sentido nacional e global ao projeto. Atuando no setor produtivo, conjuga uma atitude responsável face à viabilizaçăo iniciativa cơm a sensibilidade ante os interesses das geraçóes futuras. Outras colaboraçóes foram igualmente de muita valia. As opiniōes de Luiz Barrichelo (do Departamento de Silvicultura da ESALQ), Mauro Victor, Nelson Barbosa e Antonio Rensi Coelho trouxeram para o grupo uma longa tradiçáo em problemas florestais e, ao mesmo tempo, experiência no sofrimento para a obtençáo de recursos indispensáveis à execuçáo de projetos de florestamento.

Foram inúmeras as reunióes realizadas, com maior ou menor participaçáo dos componentes do grupo ampliado. As intervençóes de Geraldo Forbes e de James Wright ajudaram na orientaçáo dos trabalhos na linha de reflexão do IEA. Isto é, para garantir que desde sua origem o projeto fosse marcado pela interdisciplinaridade e a prospectiva. Em resumo, a principal característica do grupo foi a consciência de uma responsabilidade nacional e de longo prazo, mas também de pragmatismo.

\section{As premissas do projeto}

Contribuindo, dentro de nossas possibilidades territoriais, para a implantaçáo de grandes massas de vegetação, o Brasil pode colaborar com um programa internacional de sequestro de gás carbônico e assim alcançar vários resultados. Por meio de um projeto bem estruturado, o País se coloca em condiçōes morais de exigir contrapartidas dos países pós-industrializados - principais responsáveis pela liberaçáo e concentração de $\mathrm{CO}_{2}$ na atmosfera. Ao mesmo tempo, poderá obter uma reserva de fitomassa, de grandes proporçōes, para efeitos produtivos múltiplos de interesse nacional. Funçôes e salvaguardas foram incluídas para garantir a validade ecológica e social do projeto e torná-lo implementável em qualquer época. Na opiniáo do Prof. Aziz, nos próximos dez anos e a partir de qualquer setor preestabelecido, o Floram pode ser iniciado, já que, a despeito de seu caráter amplo dito erroneamente de "megarreflorestamento" - $\epsilon$ um somatório de projetos regionais, relacionado a uma correta tipologia de florestamentos ou reflorestamentos.

Nascido como um projeto de reflorestamento para o ambiente planetário (flor: florestas; am: ambiente; daí Floram), sigla proposta pelo Rodés, o projeto atingiu níveis de florestas sociais; florestas para reabilitaçáo de solos; florestas para bloqueio de desertificação; florestas para reperenização de drenagem; florestas híbridas de interesse sócio-econômico e cultural; florestas e bosques para bloqueio 
de conturbação; bosques e áreas verdes periurbanas; revegetaçáo e bosqueamentos viáveis para as regiōes semi-áridas brasileiras (Floram - Nordeste seco).

Essas premissas reclamam uma atençáo com as definiçōes para a compatibilidade operacional face a situaçóes tidas como antagônicas, em decorrência de preconceitos. Assim, deve-se buscar a possibilidade de uma conjugação entre a industrializaçăo de produtos florestais e a preservaçáo do meio ambiente; entre à silvicultura de clones diferenciados e a biodiversidade; entre as atividades de grandes empresas e uma "social-forestry" de pequenos e médios empreendimentos. Essa é a visão estratégica que assegura a viabilidade dos empreendimentos florestais sugeridos pelo Floram.

\section{Debate com 100 personalidades}

... decidiu-se submeter os textos elaborados a apreciação de 100 personalidades dos principais setores interessados na questão florestal.
Ao longo do segundo semestre de 1989 e graças a um esforço intenso do núcleo básico - Aziz, Rodés e Zulauf - as idéias do projeto ganharam corpo e foram revistas pelo grupo mais amplo. Sendo um projeto da sociedade - em 14 de dezembro de 1989 - decidiu-se submeter os textos elaborados à ápreciaçáo de 100 personalidades dos principais setores interessados na questáo florestal. Pessoas vinculadas à pesquisa, à problemática ecológica e ao setor produtivo - entre eles as empresas nas áreas de transformação e comercializaçăo da madeira e de empreendimentos em reflorestamento. $O$ objetivo era submeter os documentos preliminares à crítica de interessados na questáo florestal.

A jornada de discussão se realizou no dia 21 de fevereiro de 1990 , tendo se baseado nos textos previamente distribuídos (IEA/Documentos Série Ciências Ambientais, I, II e III - Projeto Floram: Primeira Aproximação). No encontro, além de serem recolhidos os comentários dos presentes, foram lidas as opinióes remetidas por carta. Os debates forneceram valiosos subsídios - que foram aproveitados no aprimoramento do projeto. Um juízo positivo sobre as idéias e objetivos do Floram ficou evidenciado.

Duas informaçóes auspiciosas foram transmitidas naquela reuniāo. Murillo Passos e Aldo Sani - respectivamente da Cia. Vale do Rio Doce e da Riocell - revelaram quie iniciátivas convergentes, no sentido preconizado pelo Floram, já estavam em andamento nas regiōes em que atuam essas empresas. A CVRD vem executando um projeto de reflorestamento numa área de um milháo de hectares $\mathrm{e} a$ Riocell, através do florestamento, vem atuando no sentido de atenuar o processo de desertificação no Rio Grande do Sul. Informaçóes alentadoras porque favorecem a idéia de que o Floram, além de um

Estudós Avinçados, 4(9) 
plano, é um incentivo a esforços descentralizados de preservaçáo do meio ambiente, através da ampliação da cobertura vegetal.

\section{Características do Floram}

Desde as primeiras discussóes em torno do projeto, ficou assentado que a mesma motivação e as características que presidiam a elaboração do Floram deveriam nortear sua execução. O que define essa motivaçáo e essas características ?

Em primeiro lugar, é a evidência de sua necessidade, ao oferecer à sociedade brasileira uma alternativa para enfrentar a questáo ambiental com uma solução viável e útil, não só à geração do presente, mas também às geraçóes futuras. Em segundo lugar, que essa missão seja desincumbida de forma interinstitucional e interdisciplinar. Quer dizer, evitando a criação de novas instituiçōes, mas compondo novas redes de talentos existentes, mantendo-os nas suas instituiçóes de origem. Interdisciplinarmente, porque se entende que a complexidade do Floram tem que ser enfrentada com a confluência de conhecimentos, como ocorreu dentro do grupo que o elaborou. Em terceiro lugar, com o compromisso da Universidade desempenhar um papel de território de encontro, onde os atores da sociedade possam convergir e livremente gerar proposiçóes de interesse da sociedade como um todo. Desta forma, estará se refletindo o interesse da sociedade brasileira em sua globalidade, de forma a que - dos mais "verdes" aos mais utilitaristas - tenham espaço para o encontro de soluçóes negociadas em função de um plano a ser apreciado e eventualmente adotado.

\section{A próxima etapa}

A terceira fase do projeto Floram está apenas iniciando. De um lado, há que se completar estudos de detalhamento. Paralelamente, é preciso levar o projeto para os maiores interéssados na sua implantaçăo. Elaborados os documentos introdutórios, o projeto é transferido para a alçada dos organismos $e$ instituiçōes especializadas existentes, das diversas regiōes do Brasil. A execuçáo do projeto depende agora da sua particularização para as regióes brasileiras, de uma estrutura em redes que favoreça uma ampla concertação entre os atores envolvidos, e da viabilização de recursos financeiros.

A particularizaçáo para as regiōes brasileiras deve permitir a análise das áreas de cada regiáo e determinar a forma peculiar de florestamento pertinente a cada área. No âmbito da USP, a ESALQ, através de seu Departamento de Ciências Florestais e do IPEF, tem uma importante 
contribuição a dar na ampliaçáo do diálogo e da cooperação para a completa descentralizaçăo das etapas subseqüentes do projeto.

A estrutura organizacional em rede combina a reuniáo dos talentos existentes em torno de uma estratégia concertada. A estrutura em rede evita a expansão parasitária das atividades-meio, valorizando as instituiçōes existentes e priorizando as metas de um programa mobilizador como o Floram.

A viabilização dos recursos financeiros depende de um conjunto de fatores que se estendem do preço da terra ao custeio da floresta. Informaçōes alentadoras, a nível internacional, revelam oportunidades de conversão da dívida junto a países credores e financiamentos junto a bancos multilaterais, orientadas à construçáo de uma aliança verde. São oportunidades ainda em fase de concretizaçáo, que em conjugaçáo com recursos do setor produtivo e dos estados podem viabilizar o programa.

O Instituto de Estudos Avançados entrega à sociedade brasileira um projeto que pode contribuir para uma soluçáo positiva de um problema mundial - a contaminação da biosfera pelo excesso de gás carbônico. Cabe agora à sociedade discuti-lo, emendar e particularizar o projeto, para otimizar seus múltiplos propósitos de interesse para as regióes brasileiras, para o País, para as naçóes vizinhas e para a sociedade humana.

Bibliografia

AB'SÁBER, Aziz. Zoneamento Ecológico e Económico da Amazônia: questōes de escala e mérodo. São Paulo, Renista IEA, Vol 3, n 5, jan./abril/1989, p. 4-20.

BRASIL FLORESTAL: Ano 2000. Diretrizes Estratégicas para o Setor Florestal Brasileiro, São Paulo, Grupo de Planejamento Estratégico Florestal, 77 p., dezembro/1981.

BROWN, Lester R. et alii State of the World,New York, W.W. Norton \& Co., 1989, 256 p.

FULLER, Kathryn S. Debt-for-Nature Swaps: a new conservation tool. EUA, in World Wildlife Fund Letter, World Wildlife Fund, 1988.

GUOJIAN, Han. Grandiosa Obra Ecológica. Peking, China, Semandrio Beijing Informan, $n^{\circ} 26$, p. 16-26, junio 26/1990.

LARREA, Roque Sevilla \& QUESADA, Alvaro Umaña. Por Que Canjear Deuda por Naturaleza ?Quito, Ecuador, Fundacion Natura, 30 p.

MCNEELY, Jeffrey A. Economics and Biological Dipersity: Developing and Using Ecomomic

Estudos Avançados, 4(9) 
Incentives to Conserve Biological Resources. Gland, Switzerland, . IUCN - International Union for Conservation of Nature and Natural Resources, 236 p., November, 1988.

MARCOVTTCH, Jacques \& RODÉS, Leopold. Grupo de Debates sobre Planejamento Estratégico para o Setor de Celulose e Papel: a experiência brasileira. Washington, EUA, Revista Cilmcia Interamericana da OEA,

Vol. 22, n 3-4, p. 24-28, julio/1982.

MINTZER, Irving. Economics of Environmental Protection. EUA, in Joumal of Policy Analysis and Management, 1988.

POSTEL, Sandra \& HEISE, Lori. Reforesting the Earth. in Brown, Lester R. et alii State of the World, New York, W.W. Norton \& Co., 1988, 256 p.

REPETTO, Robert. Promoting Envirommentally Sound Economic Progress: what the North can do, New York, WRI - World Resources Institute, 21 p., 1990.

SEDJO, Rodger A. Forests: a tool to moderate global warming ?. Washington, Enviroment, Vol. 31 (1), p. 15-20, january/february/1989.

THE WORLD BANK. Funding for the Global Enniromenent. Discussion Paper, February, 1990.

ZULAUF, Werner Eugénio. A Reversáo Florestal. Jornal Folba de S. Paulo, C.2 Cidades, 7 de dezembro de 1988. 